\title{
The Role of Nutrients in Supporting The Immune System Against Viral Infection; Newly Emerged Coronavirus (COVID- 19): A Narrative Review
}

\author{
Halgord Ali M. Farag \\ Nursing Department \\ Technical College of Applied Sciences | Research Center \\ Sulaimani Polytechnic University \\ Sulaimani, Iraq \\ halgord.farag@spu.edu.iq \\ Yousif Taha Hussein \\ Nursing Department \\ Technical College of Applied Sciences | Research Center \\ Sulaimani Polytechnic University \\ Sulaimani, Iraq \\ yousif.taha@spu.edu.iq \\ Syamand Ahmed Qadir \\ Medical Laboratory Science \\ Technical College of Applied Sciences | Research Center \\ Sulaimani Polytechnic University \\ Sulaimani, Iraq \\ syamand.qadir@spu.edu.iq
}

\author{
Hardi Rafat Baqi \\ Medical Laboratory Science \\ Technical College of Applied Sciences | Research Center \\ Sulaimani Polytechnic University \\ Sulaimani, Iraq \\ hardi.baqi@spu.edu.ic
}

Osama Hamid Shareef

Medical Laboratory Science

Medical Laboratory Science
Technical College of Applied Sciences | Research Center

Sulaimani Polytechnic University

Sulaimani, Iraq

osama.shareef@spu.edu.iq

\section{Amany El Afifi}

Clinical Pharmacy Department

Faculty of Pharmacy

Al Azhar University of Gaza

Gaza, Palestine

amany.elafifi95@gmail.com

\footnotetext{
Abdel Hamid El Bilbeisi

Clinical Nutrition Department

Faculty of Pharmacy

Al Azhar University of Gaza

Gaza, Palestine

$\underline{\text { Abedazhot@gmail.com }}$
}

\begin{tabular}{|c|}
\hline Article Info \\
\hline $\begin{array}{l}\text { Special Issue on } \\
\text { Coronavirus (COVID-19) }\end{array}$ \\
\hline DOI: \\
\hline 10.24017/covid.10 \\
\hline Article history: \\
\hline $\begin{array}{l}\text { Received: } 11 \text { May } 2020 \\
\text { Accepted: } 20 \text { May } 2020\end{array}$ \\
\hline
\end{tabular}

\begin{abstract}
Balanced nutrition is vital for peak performance of immune function, especially when a global pandemic is emerging, and there is major lack in approved treatments for it. Many nutrients and their abundance in cells induce immune function. We performed a narrative review to describe existing literature with regard to role of nutrients in supporting the immune system against viral infection including coronavirus (SARS-COV-2). PubMed, Scopus and Google Scholar databases were searched for relevant articles. This review represents a picture of the current state of the art. In
\end{abstract}


Keywords:

COVID-19,

Nutrition,

Viral infections,

Vitamins and Minerals particular, we classified the nutrients by means of their types, abundance, importance and possible antiviral effects in immune system. The macronutrients such as carbohydrates, lipids, and proteins are essential for cells to generate energy and participate in immune function as well. However, unbalanced diet with high levels of macromolecules could lead to chronic diseases that impair the body's immune abilities. The micronutrients including vitamins and minerals participate in immune system on a bigger scale that almost all body's immune mechanism depends on the expressions of micronutrients. Vitamins improve immune responses. Some vitamins include $A, D, K, B$, and $C$ enroll in antiviral mechanism of the immune cells. A group of trace elements including zinc, copper, selenium, magnesium, manganese, and iron are heavily contributed in maintaining body's immunity. The susceptibility toward the infectious diseases is highly elevated in cases of their deficiencies. Besides their antiviral roles, vitamins such as $E$ and $C$ with minerals in the cells adopt antioxidant properties that help immune cells to fight oxidative stress in the cells. Nevertheless, the high levels of minerals such as iron could threat the immune system by growing the oxidative stress. So, maintaining rich and balanced nutrition could improve body's immune function, and possibly prevent viral infections including COVID-19.

\section{INTRODUCTION}

When most people hear the word "virus" they consider of disease-causing viruses, for example, the flu, common cold, Human Immunodeficiency Viruses (HIV), chickenpox, and others. Likewise, viruses can influence many organ systems in the body, including the digestive, reproductive, and respiratory systems [1],[2]. A recent pandemic coronavirus infection began in Wuhan, Hubei's province of China and called COV-2019, later on, renamed by World Health Organization (WHO) to COVID-19 [2]. The common direct reason of death in COVID-19 is because of severe pneumonia. Additionally, pneumonia is the cause of death for individuals who develop influenza that may develop worldwide with pandemic [3].

Presently, there are no certified treatments for this novel virus. Given the enormous financial effect of viral infection, especially coronavirus treatment, alternative solutions need to be found to decrease the risks of infection and death. Various standards have been adopted to reduce the risks of spreading respiratory virus such as personal hygiene, staying at home and away from individual showing symptoms and covering sneeze and cough [4]. Fortunately, there are many other ways we can give our immune system a boost to the ideal immune function. In addition, the nutritional status of the human body could decrease the risk of viral infection and its consequences [5].

Many evidences suggest that poor nutrition diminishes the immunity, and increases the risk of infection [6],[7]. Indeed, the nutrition deficiencies lead to decrease the immune response and cause an increase in the duration and susceptibility to viral infections. The relation between nutrition and viral infection can be discussed in two ways, the impact of nutrients on the development of the humans immune system, and the relation between malnutrition and immunodeficiency [8]. Besides, the crucial role of nutrients in the immune system was confirmed by other evidence which demonstrated antiviral properties [9],[10]. Indeed, single nutrient deficiency significantly impairs the immune response and increases the susceptibility to viral infections during exposure [11],[12]. Fortunately, the human immune system is intended to fend off disorders and viruses. But unfortunately, our immune system can be 
weakened by certain things such as; medication, toxins, modern lifestyle, stress, poor nutrient, unhealthy nutrition, and lack of exercise. This keeps our bodies from successfully fending off infections. This review focuses on the evidence related to the effect of nutrient intake on immunity for fighting viral infection.

\section{LITERATURE REVIEW}

\subsection{Immune system}

The immune system keeps us healthy as we float throughout the ocean of pathogens. The immune system is spread all through the body and can be divided in to non-antigen specific (innate) and antigen-specific (adaptive) responses. The fast, non-antigen specific defense is comprised of a physical barrier like skin, antimicrobial peptidase, and mucus membrane [13]. They are naturally present and directly act as the first line to recognize and destroy pathogen via inflammatory process [13],[14]. Despite of their fast responses, they lack specificity, so, they are less active than antigen-specific response.

Antigen-specific defense includes the B lymphocyte (B Cell System), which can produce and secrete antibodies specific to infecting pathogens, and T lymphocyte (T Cell System) is cellmediated immunity and or kill virally infected cell. They are compelling in checking the scatter of infection and killing the attacking organisms. However its action is slower than nonspecific antigen, but it is responsible for producing immunological "memory", following reinfection and exposed with a similar pathogen it will generate an incredible, quick antigenspecific reaction [13],[15]. With the information regarding the novel coronavirus (SARSCoV-2) outbreak, supporting our immune system is of the highest priority. We can do this by making a couple of key adjustments.

\subsection{Effect of nutrients in immune system}

The role of nutrition to supply vigorous immunity against viral infectious has been immensely investigated. Many researches show improving nutrition has a significant role in encouraging the immune system and keeping up appropriate immune function. So we would inspire and keeping up a balance diet to help our immune capacity. The roles of specific micronutrients, vitamins and minerals, were assumed as significant and complementary roles in supporting the immune system. Moreover, the nutritional deficiencies are negatively related to immune function and cause in decreasing body resistance to infections as a result of food shortages or malnutrition [16],[17],[18]. However, excessive intake of some nutrients can also be adversely associated with immune responses [19]. Therefore, it is vital to have an adequate amount of nutrients with a variety of ingredients, to defend against pathogens in the future.

\subsection{Macro-nutrients}

\subsubsection{Carbohydrates}

Carbohydrate s are macronutrients that containing hydrogen, carbon, and oxygen [20]. Eating staple carbohydrate during daily activities induce immune system and can aid the body's recovery because they act as a fuel for immune cells [21]. For example, the anaerobic glycolysis showing an increase in lymphocytes as immune cells and detects the elevation of glucose as a fuel source for energy. Besides, the carbohydrate gives the body with around $60 \%$ of the essential energy, so when you cut them out entirely, or taking a low-carb diet, the body is going to miss them [20]. Studies suggested that ingesting 30-60 grams of carbohydrate supplements during intensive, prolonged exercise increase the counting number of blood neutrophil and monocyte, stress hormones, and anti-inflammatory cytokines molecules [22],[23],[24].

Generally, the carbohydrates mechanisms of work lead to decrease central nervous system activation and stress hormone output, lowering beta-oxidation of lipid fuels, inhibiting cytokine mRNA expression, attenuating IL-6 release from the working muscle tissue and reducing pro-inflammatory signals [24],[25]. Moreover, Jonathan Peake in a press release said that the body's stress response is reduced when having stable blood sugar levels, which in turn, moderates any undesirable mobilization of immune cells [21]. In addition, more researches 
claim that this also helps to avoid infections and illnesses [26]. On the other hand, overconsumption of carbohydrates can also be a part of harm, especially simple carbohydrates and foods with a high glycemic index [27],[28].

\subsubsection{Fats}

Fat is an essential macronutrient in the diet that can be found in animal sources in solid state like butter that is called visible fat and vegetable source in liquid state like sunflower and groundnut which named invisible fat. It provides a source of energy and assumes a significant role in both health and disease. Excessive consumption of fat gotten from animal source lifts the blood cholesterol which causes cardiovascular and other related diseases [29]. Simultaneously, these conditions are too connected to constant inflammatory polarization of $\mathrm{T}$ lymphocytes, macrophages, and chronic inflammation [30]. "Raised dietary admission of saturated fatty acids (SFAs), palmitate, and stearate unequivocally correspond with inflammation and metabolic conditions" [31]. Conversely, "unsaturated fats (oleate and linoleate), especially polyunsaturated fatty acids (PUFAs), may forestall or decrease inflammation. The amassing of saturated fatty acids (SFAs) and diacylglycerols (DAGs) can be poisonous by actuating endoplasmic reticulum stress, which additionally drives the inflammatory M1 phenotype in macrophages" [32]. Based on the previous evidence it is recommended that "the development of autoimmune disease in mice is caused by excess accumulation of cholesterol in immune cells; furthermore, the accumulation of cholesterol in antigen-presenting cells developed $\mathrm{T}$ cell preparation through antigen presentation and promoted the $\mathrm{B}$ cell proliferation factors production, thereby driving the expansion of autoreactive B cells. Eventually, it is important to note that promoting reverse cholesterol overexpressing HDL constituent consulted protection from the development of autoimmune disease" [33]. Some studies suggest that there is an interrelationship between essential fatty acid (EFA) metabolism and their capacity to respond to viral infection. In vivo and in vitro viral infection induces abnormalities of essential fatty acid metabolism. These perceptions propose that a normal level of essential fatty acid metabolism is critical in directing the viral infection response [34]. On the other hand, low degrees of cholesterol are common during the beginning periods of HIV-1 infection and related to the explicit immune system modification, proposing that hypocholesterolemia might be a helpful marker of disease progression [35].

\subsubsection{Proteins}

Proteins can make building blocks of widely diverse products as hormones, enzymes, and antibodies. Plant proteins are ordinarily by-products of vegetable oil production, so, some studies used these iso-caloric and iso-nitrogenous diet containing sesame, sunflower seed, groundnut and cottonseed as source of protein [36]. "L-Tryptophan (L-Trp) is an essential amino acid that represents a crucial role by activating aryl hydrocarbon receptor (AhR), assume a significant role in immune system regulation and antimicrobial protection [37]. Furthermore, a combination of tryptophan (Trp) with arginine (Arg) may cause a balanced immune response against infectious bursal disease" [38]. On the other hand, protein-calorie malnutrition is a causal role in increasing immune dysfunction and host susceptibility to viral infection. So on, researchers have examined the effect of protein deficiency on sensitivity to viral infection [39]. However, an expanding requirement for protein in infection disease doesn't suggest a total therapeutic strategy. Otherwise, infections should be handled appropriately and nutrition maybe used as an adjunctive treatment. While lysine supplementation to the required level, improves immune function, however, there is no enough evidence to show clinical outcomes [40]. Some studies demonstrate "a critical role of three essential proteins including leucine, L-arginine (Arg), and L-glutamine (Gln) every one of which has been recently appeared to slow muscle proteolysis and could synergistically modify the course of muscle wasting in patients infected with (AIDS) by the decrease in the HIV viral and an increase in CD3 and CD8 cells" [41],[42].

\subsection{Micronutrients}




\subsubsection{Vitamins \\ 2.4.1.1 Vitamin A}

Vitamin A is essential for protecting epithelial, normal growth, and maintaining the vision [43], it acts in improving immune function either in innate or adaptive immune responses [44]. Hypovitaminosis A is known as nutritionally acquired immune deficiency disorder as a result of weakened antibody responses to protein antigens, resulted in epithelial damage in Newcastle and rotavirus infection [45], [46]. Study indicates that increased antibody response in vitamin A supplementation was observed after measles [47],[48] and anti-rabies vaccination [49], and anti-rabies vaccination [49]. More study is required in terms of antiviral effect regarding newly emerged coronavirus.

Generally, Vit A is known to influence gene translation, ordinarily encourage the creation of interleukins 4 and 5 (IL-4-5) and differentiation toward T helper 2 (th 2) cell [50]. The IL-4 was found to decrease the vulnerability of Vero E6 cells to SARS-COV and inhibiting its replication through down-regulation of "angiotensin-converting enzyme" [51], [52]. Conflicting with this outcome, treatment with IL-4 in infected viral influenza in mice repressed both primary and secondary antiviral immune reaction [53]. Thus, the antiviral mechanism effect of Vit A can contributes to the IL-4 intervened suppressive impact. Considering recent viral infection COVID-19, where no successful preventive and treatment, Vit A may be one of the vulnerable choices. Further studies are required.

\subsubsection{Vitamin $D$}

Vitamin D (Vit D) is a fat-soluble vitamin. The major source is derived from UV (Ultra Violet) light-induced conversion of its precursor 7-dehydrocholesterol under the skin to cholecalciferol, Vit D3 [54]. Study shows that "the active form of Vit D is triggered by UV$B$ radiations and leading to increase production of antiviral peptidase, increasing the oxidative burst potential of microphage and prevent the excessive expression of inflammatory cytokines" [55],[56]. It has been known that Vit D enhances the innate immunity by upregulation of the expression and excretion of potent antimicrobial peptides in immune cells and epithelial lining, which boosts mucosal defense again viral infection [57]. The protective effect of Vit D in response to viral infection has been proved by many studies. Vit D plays important role in mediating the immune system's reaction to entry pathogens [58]. Recently, study suggests that a population with Vit D deficiency is prone to frequent viral infection compared to a non-deficient population [59].

Hypovitaminosis D is associated with viral respiratory infection [60], human immune deficiency virus (HIV) [61], as well as upper respiratory tract infection (URTI) including influenza [58]. Taken in to account the moderately high doses up to 2000 to $5000 \mathrm{IU}$ per day can be taken for a year [62],[63],[64]. However, the antiviral properties of Vit D have not been finally established, it may be linked to the primary circulating form of Vit D in the kidney and other cell types including immune cells to its biologically active compound calcitriol by 1- $\alpha$ hydroxylase enzyme [65]. Vit D due to its Vit D receptors response elements are expressed in immune cells such as antigen-presenting-cell, monocyte, B and T cells [65],[66]. Additionally, active Vit D has been associated with the expression of specific micro RNAs (miRs), which is associated with redundant pro-inflammatory responses under the pathological situation [60]. There is a possibility that Vit D may slow non-specific effect on severe viral respiratory infections.

\subsubsection{Vitamin $E$}

Vitamin E (Tocopherol) is a vitamin that dissolves in fat. An antioxidant property of vitamin E has an important function in the human organ, which means that it assists to slowdown cells from damage [67]. Vitamin E regulates T-cell functions either directly by affecting $\mathrm{T}$ cell membrane integrity and/or cell division, and indirectly regulate $\mathrm{T}$ cell function by influencing inflammatory created from other immune cells [68]. In animal study hypovitaminosis $\mathrm{E}$ has shown a significant effect on the human immune system and resulted in enhancing immune function including resistance to bacterial and viral infection [69]. Other shows that, 
hypervitaminosis E significantly intensified influenza viral clearance in aged mice compared to young mice [68],[70],[71]. Taken together, the outcome suggests that vitamin $\mathrm{E}$ is a significant supplement for keeping up the immune system particularly in the aged group.

Furthermore, the protective impact of vitamin $\mathrm{E}$ in the treatment of chronic viral hepatitis and viral replication has been proved [72]. Also, moderate increase by vitamin $\mathrm{E}$ in natural killer (NK) cells is participating in its beneficial effect [73],[74]. Also, evidence displayed that viral infection changes the redox status of the host cell. These changes among pro-oxidant and antioxidant activity play an important role in various cell pathways that are abused by viral for their publication and subsequently the progression and severity of virus-induced disease [75]. Based on the previous evidence it is recommended that vitamin $\mathrm{E}$ is an important antioxidant that modulates immune function as it influences have helplessness to infection disease, for example, respiratory system [69] as a sign of newly diagnosed COVID-19.

\subsubsection{Vitamin $\mathrm{K}$}

Vitamin $\mathrm{K}$ is one of the fat-soluble vitamins [76]. Vitamin $\mathrm{K}$ plays key roles in different physiological functions [77]. It can also act as a coenzyme of some plasma proteins and affect immune parameters, particularly $\mathrm{T}$ cells and inflammatory pathways [78]. Vitamin $\mathrm{K}$ has been found to have anti-inflammatory activity directed through inhibition of proinflammatory transcriptional factor, Nuclear factor-kappa B (NF- $\mathrm{B})$ signaling pathway [79]. "Several in vitro studies also showed that vitamin $\mathrm{K} 2$ inhibits the production of prostaglandins and major pro-inflammatory cytokines including IL-1, IL-6, TNF- $\alpha$ ” [74],[80],[81]. Consistent with these results, increases in cytokine levels are directly correlated with increase viral load, increased mortality, and severity of the disease [82]. These results suggest that inhibition of the pro-inflammatory cytokines by vitamin $\mathrm{K}$ may contribute to viral clearance and tissue resolution [83]. Inconsistent with these results, "various studies suggest that treatment of cells with TNF- $\alpha$ plays a protective role in viral infection and can inhibit the replication of human immunodeficiency virus type 1 (HIV-1), vesicular stomatitis virus, encephalomyocarditis virus, and herpes simplex virus in a dose-dependent manner and can prevent the development of cytopathic effects. Also, they suggest that TNF- $\alpha$ serves as the first line of defense against influenza virus infection in the natural host" [84],[85]. Furthermore, our literature search was unable to identify a proven mechanism examining the use of vitamin $\mathrm{K}$ for the treatment of specific viral infections. However, study revealed that vitamin $\mathrm{K}$ can indirectly affect immunity through complement system pathways [86].

\subsubsection{Vitamin B}

The B-complex vitamins are class of water-soluble vitamins. They play important roles in cell metabolism and in the maintenance of immune homeostasis [87]. It has been reported that the antibody formation to influenza virus PR-8 in the rat was markedly impaired in pantothenic acid, vitamin B5- and pyridoxine, vitamin B6- deficient rats. But A pronounced thiamine, vitamin B1, deficiency failed to affect antibody production [88],[89].

The most recent studies showed that "the total number of NK and CD8+ T cells was decreased markedly in patients with SARS-CoV-2 infection and the function of NK and CD8+ T cells was exhausted with the increased expression of NKG2A in COVID-19 patients" [90]. It was also reported the potential involvement of NK cells in the previous severe acute respiratory syndrome (SARS) disease in China in November 2002 [91]. These data show the importance of vitamin $\mathrm{B}$ in improving the immune response and consequently may contribute to virus elimination and disease control in COVID-19 patients.

\subsubsection{Vitamin $C$}

Vitamin C, also known as L-ascorbic acid, is a water-soluble vitamin [92]. Several investigations indicated that vitamin $C$ is an essential factor for the anti-viral immune responses through increasing production of anti-viral cytokine, interferon (IFN)- $\alpha / \beta$ especially against influenza A virus (H3N2) at the early time of infection [93],[94]. Similarly, in another animal study, vitamin $\mathrm{C}$ deficiency increased the lung pathology of influenza virus-infected 
gulo-/- mice. The authors suggest that vitamin $\mathrm{C}$ is required for an adequate immune response in limiting lung pathology after influenza virus infection [95]. In addition to demonstrate the activity against influenza and HIV, vitamin $\mathrm{C}$ has been documented to have inhibitory activity against several other viruses including avian RNA tumor viruses, herpesviruses and paramyxoviruses, Venezuelan equine encephalitis, parvovirus, rabies virus and human lymphotropic virus type 1 (HTLV-1) among others [96],[97].

However, a review of the current evidence on the ameliorative effect of vitamin $\mathrm{C}$ to alleviate the symptoms of the common cold suggests that the role of vitamin $\mathrm{C}$ in the treatment of common cold should be reconsidered due to consistency of the previous results [98],[99]. Moreover, high dose intravenous vitamin $\mathrm{C}$ treatment has been shown to significantly improve symptoms in people with severe viral infections [100].

\subsection{Minerals}

A group of trace elements is critical in maintaining the immune system. These are zinc, copper, selenium, magnesium, manganese, and iron. Any variations in the amount of these metals induce immune function in different ways, including antibody responses, cell-mediated immunity, and the activity of natural killer (NK) cells. A well-functioning immune system is significant for cells to eliminate or reduce infections. This is particularly important for all people in the time of the global pandemic. So, keeping the optimum levels of all nutrients, including trace elements for the maximum immune function should be taken seriously. Moreover, these trace elements such as selenium and zinc can affect the genetics of a viral pathogen other than the host cells and efficiently impair the replication of many RNA viruses [101],[102].

\subsubsection{Zinc}

Zinc $(\mathrm{Zn})$ is one of the most investigated trace elements for its affection on the host immune system. The susceptibility to infectious diseases has been noted to increase in Zn deficiency syndromes [103]. The effect of $\mathrm{Zn}$ deficiency in 30 days of suboptimal $\mathrm{Zn}$ levels feeding period in mice led the thymus size to be reduced, macrophages and lymphocytes in spleen to be depleted [103],[104]. The health of children with pneumonia (1 month to 5 years) who supplemented with $\mathrm{Zn}$ has improved in terms of duration of the illness, oxygen saturation, and respiratory rate when compared to the placebo group [106]. Lower than normal levels of $\mathrm{Zn}$ also have been linked to the decreased antibody responses and function of T-cell [107]. While the restoring of $\mathrm{Zn}$ levels to normal caused the status of the immune system to be restored as well [108]. Higher than normal levels of Zn also suppress the immune system by decreasing the activities of polymorphonuclear leukocytes, $\mathrm{T}$ - cell proliferation to mitogen, and antibody production [109]. Therefore, $\mathrm{Zn}$ either high or low levels adversely alters the immune function.

\subsubsection{Copper}

One of the essential nutrients for humans is Copper $(\mathrm{Cu})$, however, the deficiency of $\mathrm{Cu}$ is a rare condition. $\mathrm{Cu}$ participates in immune function by developing and differentiating immune cells [110]. Cu demonstrates antiviral effects in-vitro. A study showed the inhibition effect of thujaplicin-copper on the replication of human influenza viruses [111]. While the in-vivo effect of $\mathrm{Cu}$ regulates the lifecycle of the influenza virus [112]. Animals with deficient $\mathrm{Cu}$ have a higher susceptibility to bacterial, viral, and parasitic infections [113]. Menkes syndrome in children which is a genetic disease of $\mathrm{Cu}$ malabsorption causes death due to the infectious bronchopneumonia [114]. Long term high $\mathrm{Cu}$ intake leads to the improvement of antioxidant status [115]. Human studies showed the effect of a low $\mathrm{Cu}$ diet on the immune system. Healthy adults with low $\mathrm{Cu}$ intake caused lymphoproliferative responses to mitogen to decrease. The IL-2 receptor's secretion decreased as well. But, the B-cells increased with the unchanged numbers of T-cells. The neutrophil phagocytic function remained unchanged [116]. Although normal levels of $\mathrm{Cu}$ are critical for the immune system, the exact mechanism 
of its participation is not quite clear. Moreover, the biochemical activities of $\mathrm{Cu}$ might be important in reducing oxidative stress

\subsubsection{Selenium}

Selenium (Se) an important trace element with anti-inflammatory properties [116],[117]. Se deficiency leads to oxidative stress in the host that is an overabundance of the free radical production and other oxidants while comparing to the defensive antioxidants. This stress affects the host cells in many ways. The free radicals damage 10,000 DNA bases daily and some of them are not repaired [119]. Se supplementation increases antiviral activity [117]. Broome et al. searched for the effect of an increase in Se intake by (50-100 $\mu \mathrm{g} / \mathrm{day})$, the result showed an improvement in the immune function of adults [120]. The effect is caused by increased plasma concentration of Se, lymphocyte phospholipid and the activity of cytosolic glutathione peroxidase [120]. A randomized control trial (RCT) lasted 12 weeks, healthy adults with suboptimal Se levels $(<110 \mathrm{ng} / \mathrm{ml})$ were supplemented with daily doses of yeast enriched Se capsules. The results showed favored and un-favored effects [121]. The T-cell proliferation of the Se supplemented group increase based on the daily dose, but in an opposing effect the granzyme B content of CD8 cells decreased [121]. Furthermore, Se supplementation showed an effect on the skin response delayed-type hypersensitivity (DTH) [122]. A control group in this study (low Se) increased the numbers of NK cells and induced anergy in skin responses DTH, while the responses in the treated group (high Se) were normal, proposing that Se blocks the induction of DTH anergy [122]. The increase in susceptibility toward pathogens in Se deficiency might be because of decreasing the production of antibodies and the impaired response of lymphoproliferative [123].

\subsubsection{Magnesium}

Magnesium (Mg) is important micronutrients, and it has many roles in biological systems, specifically in immune systems [124]. Many studies propose that Mg has a role in developing an immune response against viral infections [125]. It has an immense influence on many processes of the immune function, including synthesis of immunoglobulins, immune cell adherence, Immunoglobulin M (IgM) lymphocyte binding, antibody dependent cytolysis, macrophage response to lymphokines, and T helper-B cell adherence [126].

\subsubsection{Manganese}

Manganese ( $\mathrm{Mn})$ is a widely distributed metal among mammalian tissues and it participates in many processes such as antioxidant defenses, immune regulation, neuronal function, and reproduction [126],[127]. Although, Manganese's exact contribution to innate immunity stay undefined, yet, some findings suggest its involvement in the defense system of the host cells against DNA viruses [129]. Mn showed activities in host immunity against DNA viruses by increasing cGAS DNA sensor and STING the adaptor protein [130]. The production of cytokine in Mn-deficient mice was diminished and was more exposed to DNA viruses [130]. $\mathrm{Mn}$ is fundamental for $\mathrm{Mn}$ superoxide dismutase (SOD2) metalloenzyme, it also regulates many Mn-dependent enzymes [131],[132].

\subsubsection{Iron}

Iron $(\mathrm{Fe})$ is needed for the activities of both the pathogens and host cells [133]. Many studies prove that iron is a major element for good immune function [134]. Fe metabolism presents the dynamic interaction of antioxidants and oxidative stress in many pathophysiological processes [135]. The deficiency of Fe impairs the immune function of host cells, while the Fe overload leads to oxidative stress that generates viral mutations [136]. The catalase enzyme converts hydrogen peroxide into harmless water and oxygen in two steps in which the reduction of the hydrogen peroxide is done by Fe [137]. Fe deficiency is a risk factor for developing recurrent acute respiratory tract infections [138]. 


\section{CONCLUSION}

To recap our revision, the type of nourishment with the consistency of both macronutrients and micronutrients has a crucial role in strengthening our immune system. To avoid the virulence activity of the novel type of SARS-CoV-2 and other pathogens, the immune system in the human body has to be induced and supported via valuable nutrients. As were obviously observed in the most recovered cases of COVID-19, its immune system lonely which overcomes the virus. Thus, to maintain and strengthen this defense line in our body, the right balance of the caloric intakes, vitamins and minerals have to be kept. In addition, it's noteworthy that the immune system is significantly influenced by both the malnutrition and over nutrition.

\section{REFERENCE}

[1] Y. Yang, S. Islam, J. Wang, Y. Li, and X. Chen, "Traditional Chinese Medicine in the Treatment of Patients Infected with 2019-New Coronavirus (SARS-CoV-2): A Review and Perspective,” vol. 16, 2020.

[2] "World Health Organization Influenza (Seasonal). Available online: https://www.who.int/news-room/fact sheets/detail/influenza-(seasonal) (accessed on Mar 2, 2020).".

[3] N. Zhu et al., "A Novel Coronavirus from Patients with Pneumonia in China, 2019," N Engl J Med, vol. 10, no. 1056 , pp. 1-7, 2020

[4] "U.S. Centers for Disease Control Take 3 Actions to Fight Flu. Available online: https://www.cdc.gov/flu/prevent/preventing.htm (accessed on Mar 2, 2020)."

[5] N. S. SCRIMSHAW, C. E. TAYLOR, and J. E. GORDON, "NUTRITION CLASSICS THE AMERICAN JOURNAL OF THE," vol. 237, pp. 367-403, 1968.

[6] P. Katona and J. Katona-apte, “The Interaction between Nutrition and Infection,” vol. 90024, 2008.

[7] M. A. Beck and O. A. Levander, "Host Nutritional Status and Its Effect on a Viral Pathogen," J. Infect. Dis., vol. 182, pp. 93-96, 2000

[8] A. Itoya et al., "Audit Of The Lifestyle Effects Of Scig On Patients With," Intern. Med. J., vol. 48, 2018.

[9] A. S. Bansal, A. S. Bradley, K. N. Bishop, S. Kiani-alikhan, and B. Ford, "Brain, Behavior , and Immunity Chronic fatigue syndrome, the immune system and viral infection," Brain Behav. Immun., vol. 26, no. 1, pp. 24-31, 2012.

[10] R. M. L. Colunga Luciano, M. Berrill, and P. E. Marik, “The antiviral properties of vitamin C," Expert Rev. Anti. Infect. Ther., vol. 18, no. 0, pp. 99-101, 2020.

[11] M. J. Rytter, L. Kolte, A. Briend, H. Friis, and V. B. Christensen, "The Immune System in Children with Malnutrition - A Systematic Review," PLoS One, vol. 9, no. 8, p. e105017, 2014.

[12] M. Gleeson, Exercise, nutrition and immunity. Woodhead Publishing Limited, 2013.

[13] Murphy, K.; Weaver, C. Janeway's Immunobiology, 9th ed.; Taylor \& Francis: New York, 2017; pp. 1-35.

[14] Staines, N. Brostoff, J. and James, K. (1993). Introducing Immunology, 2nd Edition, Mosby, London. .

[15] N. Thomas et al., "The immune system as a biomonitor: explorations in innate and adaptive immunity," Interface Focus, vol. 3, no. 2, 2013.

[16] A. C. Carr and S. Maggini, "Vitamin C and Immune Function," Nutrients, vol. 9, no. 1211, pp. 1-25, 2017.

[17] A. F. Gombart, A. Pierre, and S. Maggini, "A Review of Micronutrients and the Immune System - Working in Harmony to Reduce the Risk of Infection," Nutrients, vol. 12, no. 1, pp. 2-36, 2020.

[18] P. C. Calder and A. A. Jackson, "Undernutrition, infection and immune function," Nutr. Res. Rev., vol. 13 , no. 1, pp. 3-29, 2000

[19] L. Zhang and Y. Liu, "Potential Interventions for Novel Coronavirus in China: A Systemic Review," $J$. Med. Virol., vol. 92, no. 5, pp. 479-90, 2020.

[20] K. Karacabey and N. Ozdemir, "Obesity \& Weight Loss Therapy,” J. Obes. Weight Loss Ther., vol. 2, no. 9, 2012.

[21] J. Peake, "Immune system recovery after exercise," J. Appl. Physiol., vol. 122, no. 5, pp. 1077-1087, 2017.

[22] G. Davison and M. Gleeson, "Infl uence of Acute Vitamin C and / or Carbohydrate Ingestion on Hormonal , Cytokine, and Immune Responses to Prolonged Exercise," Int. J. Sport Nutr. Exerc. Metab., vol. 15, no. 5, pp. 465-479, 2005.

[23] D. C. Nieman et al., "Research in Sports Medicine: Influence of Carbohydrate on Immune Function Following 2 h Cycling," Res. Sport Med., vol. 14, no. 3, pp. 225-237, 2006.

[24] D. C. Nieman, "Immunonutrition support for athletes," Nutr. Rev., vol. 66, no. 6, pp. 310-320, 2008.

[25] D. C. Nieman and S. H. Mitmesser, "Potential Impact of Nutrition on Immune System Recovery from Heavy Exertion : A Metabolomics Perspective,” Nutrients, vol. 9, no. 5, p. 513, 2017.

[26] "Queensland University of Technology.," in Carbs during workouts help immune system recovery. $\begin{array}{ccccc}\text { ScienceDaily. } & \text { Retrieved } & \text { May, } & \text { 2020, } & \text { from }\end{array}$ https://www.sciencedaily.com/releases/2017/02/170216103926.htm, 2017.

[27] N. Esser, S. Legrand-Poels, J. Piette, A. J. Scheen, and N. Paquot, "Inflammation as a link between obesity, metabolic syndrome and type 2 diabetes," Diabetes Res. Clin. Pract., vol. 105, no. 2, pp. 141-150, 2014.

[28] R. E. Smith, K. Tran, K. M. Richards, and R. Luo, "Dietary Carbohydrates that Modulate the Immune System," Clin. Immunol. Endocr. Metab. Drugs, vol. 2, no. 1, pp. 35-42, 2015. 
[29] A. Nigam, "Consumption of fat in indian diet," vol. 20, no. January 2000, pp. 58-61, 2000.

[30] M. J. Hubler and A. J. Kennedy, "ScienceDirect Role of lipids in the metabolism and activation of immune cells," J. Nutr. Biochem., vol. 34, pp. 1-7, 2016.

[31] C. L. Kien and J. Y. Bunn, "Gender Alters the Effects of Palmitate and Oleate on Fat Oxidation and Energy Expenditure," vol. 16, no. 1, pp. 29-33, 2008.

[32] E. Reticulum, S. Mediated, E. K. Anderson, A. A. Hill, and A. H. Hasty, "Cell Biology / Signaling Stearic Acid Accumulation in Macrophages Induces Toll- Like Receptor 4 / 2-Independent Inflammation Leading to," 2015.

[33] A. Ito et al., "Cholesterol Accumulation in CD11c + Immune Cells Is a Causal and Targetable Factor in Autoimmune Article Cholesterol Accumulation in CD11c + Immune Cells Is a Causal and Targetable Factor in Autoimmune Disease," Immunity, vol. 45, no. 6, pp. 1311-1326, 2016.

[34] R. Article, "Essential Fatty Acids, Immunity and Viral Infections," pp. 145-151, 1990.

[35] E. Human and D. Ph, "Hypocholesterolemia Is Associated With Immune Dysfunction in Early Human Immunodeficiency Virus-1 Infection," vol. 94, no. May, pp. 515-519, 1993.

[36] G. M. Suliman, S. A. Babiker, and H. M. Eichinger, "Effect of diet-protein source on lamb fattenin,” Res. J. Agric. Biol. Sci., vol. 3, no. 5, pp. 403-408, 2007.

[37] V. Mehraj and J. Routy, "Tryptophan Catabolism in Chronic Viral Infections : Handling Uninvited Guests," pp. 41-48, 2015.

[38] P. Taylor, M. Emadi, F. Jahanshiri, K. Kaveh, A. Ideris, and A. R. Alimon, "Nutrition and immunity: the effects of the combination of arginine and tryptophan on growth performance, serum parameters and immune response in broiler chickens challenged with infectious bursal disease vaccine Nutrition and immunity: the effects of t," no. April 2015, pp. 37-41, 2011.

[39] A. Beck, N. Carolina, and T. F. Porter, "The role of nutrition," vol. 2863, no. 96, pp. 683-690, 1996

[40] A. V Kurpad, "The requirements of protein \& amino acid during acute \& chronic infections," no. August, pp. 129-148, 2006.

[41] A. W. Using, A. A. Randomized, P. Study, R. H. Clark, and G. Singh, "Communications Acquired," pp. 133-139, 2014.

[42] J. Rappaport, J. Joseph, S. Croul, G. Alexander, and L. Del Valle, "Molecular pathway involved in HIV-1induced CNS pathology : role of viral regulatory protein, Tat," no. 406, 1999.

[43] S. A. Tanumihardjo, "Vitamin A : biomarkers of nutrition for development $1-4$," Am. J. Clin. Nutr., vol 94, no. 2, pp. 658-665, 2011.

[44] L. Alvarez-rodriguez, M. Lopez-hoyos, M. Garcia-unzueta, J. A. Amado, and P. Mun, "Age and low levels of circulating vitamin D are associated with impaired innate immune function," J. Leukoc. Biol., vol. 91, no. 5, pp. 829-838, 2012

[45] B. Y. R. D. Semba, "Vitamin A and human immunodeficiency," Proc. Nutr. Soc., vol. 56, no. 1B, pp. 459469, 1997.

[46] F. AHMED1, D. B. JONES', and A. A. JACKSON, "Effect of vitamin A deficiency on the immune response to epizootic diarrhoea of infant mice ( EDIM ) rotavirus infection in mice," $B r . J . ~ N u t r$. , vol. 65, no. 3, pp. 475-485, 1991.

[47] Y. Hm, M. Mao, and C. Wan, "Vitamin A for treating measles in children ( Review )," Cochrane Database Syst. Rev., vol. 5, pp. 85-86, 2005.

[48] C. R. Sudfeld, Ã. A. M. Navar, and N. A. Halsey, "Effectiveness of measles vaccination and vitamin A treatment," Int. J. Epidemiol., vol. 39, no. 1, pp. 48-55, 2010.

[49] F. Q. Siddiqui, M. M. Ahmad, F. Kakar, S. Akhtar, and A. . Dil, "The role of vitamin A in enhancing humoral immunity produced by antirabies vaccine," EMHJ - East. Mediterr. Heal. J., vol. 7, no. 4-5, pp. 799-804, 2001

[50] S. B. Dadon and R. Reifen, "Vitamin A and the epigenome," Crit. Rev. Food Sci. Nutr., vol. 57, no. 11, pp. 2404-2411, 2017

[51] S. Lin, P. Shu, C. Chang, A. Ng, C. Hu, and E. Alerts, "IL-4 Suppresses the Expression and the Replication of Hepatitis B Virus in the Hepatocellular Carcinoma Cell Line Hep3B," J. Immunol., vol. 171, no. 9, pp. 4708-4716, 2003

[52] A. De Lang, A. D. M. E. Osterhaus, and B. L. Haagmans, "Interferon- $\gamma$ and interleukin-4 downregulate expression of the SARS coronavirus receptor ACE2 in Vero E6 cells," Virology, vol. 353, no. 2, pp. 474$481,2006$.

[53] D. A. Wahl et al., "A global representation of vitamin D status in healthy populations," Arch. Osteoporos., vol. 7, no. 1-2, pp. 155-172, 2012

[54] M. T. Zdrenghea, H. Makrinioti, C. Bagacean, A. Bush, S. L. Johnston, and L. A. Stanciu, "Vitamin D modulation of innate immune responses to respiratory viral infections," Rev. Med. Virol., vol. 27, no. e1909, pp. 1-12, 2017.

[55] C. Palacios and L. Gonzalez, "Is vitamin D deficiency a major global public health problem?," J. Steroid Biochem. Mol. Biol., vol. 144, pp. 138-145, 2013.

[56] T. Wang et al., "Direct and Indirect Induction by 1 , 25-Dihydroxyvitamin D 3 of the Innate Immune Pathway Defective in Crohn Disease * $\square$, , J. Biol. Chem., vol. 285, no. 4, pp. 2227-2231, 2010.

[57] A. J. J. Cannell et al., "Epidemic influenza and vitamin D," Epidemiol. Infect., vol. 134, no. 6, pp. 1129$1140,2006$.

[58] R. Jayawardena, P. Sooriyaarachchi, M. Chourdakis, C. Jeewandara, and P. Ranasinghe, "Enhancing immunity in viral infections, with special emphasis on COVID-19: A review," Diabetes Metab. Syndr. Clin. Res. Rev., 2020. 
[59] J. F. Arboleda and S. Urcuqui-inchima, "Vitamin D-Regulated MicroRNAs: Are They Protective Factors against Dengue Virus Infection?," Adv. Virol., vol. 2016, pp. 1-14, 2016.

[60] J. Teichmann et al., "Osteopenia in HIV-infected Women Prior to Highly Active Antiretroviral Therapy," J. Infect., vol. 46, no. 4, pp. 221-227, 2003.

[61] E. Marcinowska-Suchowierska, M. Kupisz-Urbanska, J. Lukaszkiewicz, P. Płudowski, and G. Jones, "Vitamin D Toxicity - A Clinical Perspective," Front. Endocrinol. (Lausanne)., vol. 9, no. September, p. $550,2018$.

[62] G. Esmat et al., "Impact of Vitamin D Supplementation on Sustained Virological Response in Chronic Hepatitis C Genotype 4," J. Interf. Cytokine Res., vol. 35, no. 1, pp. 49-54, 2015.

[63] N. X. Hoan et al., "Vitamin D deficiency and hepatitis viruses-associated liver diseases: a literature review," World J. Gastroenterol., vol. 24, no. 4, pp. 445-460, 2018.

[64] B. Prietl, G. Treiber, T. R. Pieber, and K. Amrein, "Vitamin D and Immune Function," Nutrients, vol. 5, no. 7, pp. 2502-2521, 2013.

[65] J. A. Beard, A. Bearden, and R. Striker, "Vitamin D and the anti-viral state," J. Clin. Virol., vol. 50, no. 3, pp. 194-200, 2011.

[66] S. Rizvi, ST. Raza, AA. Faizal Ahmed, S. Abbas, F. Mahdi "The role of vitamin E in human health and some diseases," Sultan Qaboos University Medical Journal., vol.14, no. 2, pp. e157, 2014.

[67] M. G. Hayek et al., "Vitamin E Supplementation Decreases Lung Virus Titers in Mice Infected with Influenza," J. Infect. Dis., vol. 176, no. 1, pp. 273-276, 1997.

[68] E. D. Lewis, S. N. Meydani, and D. Wu, "Critical Review Regulatory Role of Vitamin E in the Immune System and In fl ammation,” IUBMB. Wiley Online Libr., pp. 487-494, 2018.

[69] M. P. Look et al., "Interferon / antioxidant combination therapy for chronic hepatitis C — a controlled pilot trial," Antiviral Res., vol. 43, no. 2, pp. 113-122, 1999.

[70] P. Andreone et al., "Vitamin E as treatment for chronic hepatitis B : results of a randomized controlled pilot trial," Antiviral Res., vol. 49, no. 2, pp. 75-81, 2001

[71] A. V. Herbay, W. Stahl, C. Niederau, and H. Sies, "Vitamin E Improves the Aminotransferase Status of Patients Suffering from Viral Hepatitis C: A Randomized, Double-Blind, Placebo-Controlled Study," Free Radic. Res., vol. 27, no. 6, pp. 599-605, 1997.

[72] S. N. Han et al., "Vitamin E supplementation increases T helper 1 cytokine production in old mice infected with in - uenza virus," Immunolgy, vol. 100, no. 4, pp. 487-493, 2000.

[73] S. N. Han and S. N. Meydani, “Antioxidants, Cytokines, and Influenza Infection in Aged Mice," J. Infect. Dis., vol. 182, no. s1, pp. 74-80, 2000.

[74] R. Sgarbanti et al., "Intracellular Redox State as Target for Anti-Influenza Therapy: Are Antioxidants Always Effective?," Curr. Top. Med. Chem., vol. 14, no. 22, pp. 2529-2541, 2014.

[75] N. Namazi and B. Larijani, "Vitamin K and the Immune System," Nutr. Immun., pp. 75-79, 2019.

[76] Y. Ohsaki, H. Shirakawa, K. Hiwatashi, Y. Furukawa, Mi. Takeo, and M. Komai, "Vitamin K Suppresses Lipopolysaccharide-Induced Inflammation in the Rat Vitamin K Suppresses Lipopolysaccharide-Induced Inflammation in the Rat," Biosci. Biotechnol. Biochem., vol. 70, no. 4, pp. 926-932, 2006.

[77] R. Checker, D. Sharma, S. K. Sandur, and N. M. Khan, "Vitamin K3 suppressed infl ammatory and immune responses in a redox-dependent manner," Free Radic. Res., vol. 45, no. 8, pp. 975-985, 2011.

[78] S. Tanaka et al., "Vitamin K 3 attenuates lipopolysaccharide-induced acute lung injury through inhibition of nuclear factor- k B activation," Clin. Exp. Immunol., vol. 160, no. 2, pp. 283-292, 2010.

[79] M.-H. Pan et al., "Inhibition of TNF- $\alpha, I L-1 \alpha$, and IL-1 $\beta$ by Pretreatment of Human MonocyteDerivedMacrophages with Menaquinone-7 and Cell Activation with TLRAgonists In Vitro," J. Med. Food, vol. 17 , no. 9, pp. 663-669, 2016.

[80] E. Usedom, L. Neidig, and H. B. Allen, "Psoriasis and Fat-soluble Vitamins : A Review," J. Clin. Exp. Dermatol. Res., vol. 8, no. 5, 2017.

[81] E. Parlak, A. Ertürk, Y. Çağ, E. Sebin, and M. Gümüşdere, "The effect of inflammatory cytokines and the level of vitamin D on prognosis in Crimean-Congo hemorrhagic fever," Int J Clin Exp Med, vol. 8, no. 10, pp. 18302-18310, 2015.

[82] R. Espín-palazón, A. Martínez-lópez, F. J. Roca, and A. López-, "TNF a Impairs Rhabdoviral Clearance by Inhibiting the Host Autophagic Antiviral Response," PLOS Pathog., vol. 12, no. 6, p. e1005699, 2016.

[83] A. S. Using and M. Lacking, "Tumor Necrosis Factor- (TNF-) Plays a Protective Role in Acute Viral Myocarditis in Mice A Study Using Mice Lacking TNF-_," Circulation, vol. 103, no. 5, pp. 743-750, 2001.

[84] S. H. Seo, O. Goloubeva, and R. Webby, "Characterization of a Porcine Lung Epithelial Cell Line Suitable for Influenza Virus Studies,” J. Virol., vol. 75, no. 19, pp. 9517-9525, 2001.

[85] A. M. Blom, B. O. Villoutreix, and B. Dahlbäck, "Complement inhibitor C4b-binding protein — friend or foe in the innate immune system ?," Mol. Immunol., vol. 40, no. 18, pp. 1333-1346, 2004

[86] K. Yoshii, K. Hosomi, K. Sawane, and J. Kunisawa, "Metabolism of Dietary and Microbial Vitamin B Family in the Regulation of Host Immunity," Front. Nutr., vol. 6, no. 48, 2019.

[87] A. E. Axelrod and S. Hopper, "Effects of Pantothenic Acid, Pyridoxine and Thiamine Deficiencies upon Antibody Formation to Influenza Virus PR-8 in Rats1,” J. Nutr., vol. 72, no. 3, pp. 325-330, 1960.

[88] J. Tamura et al., "Immunomodulation by vitamin B12 : augmentation of CD8 p T lymphocytes and natural killer ( NK ) cell activity in vitamin B12-deficient patients by methyl-B12," Clin. Exp. Immunol., vol. 116, no. 1, pp. 28-32, 1999.

[89] M. Zheng et al., "Functional exhaustion of antiviral lymphocytes in COVID-19 patients," Cell. Mol. 
Immunol., pp. 7-9, 2020.

[90] "The Involvement of Natural Killer Cells in the Pathogenesis of Severe Acute Respiratory Syndrome," Am. J. Clin. Pathol., vol. 121, no. 4, pp. 507-511, 2004

[91] Y. Li, H. E. Schellhorn, and A. Szent-gyorgyi, "New Developments and Novel Therapeutic Perspectives for Vitamin C 1, 2," J. Nutr., vol. 137, no. 10, pp. 2171-2184, 2007.

[92] Y. Kim et al., "Vitamin C Is an Essential Factor on the Anti-viral Immune Responses through the Production of Interferon- $\alpha / \beta$ at the Initial Stage of Influenza A Virus ( H3N2 ) Infection," Immune Netw., vol. 13, no. 2, pp. 70-74, 2013.

[93] M. Wu, M. He, and Y. Kang, "Vitamin C supplementation improved the efficacy of foot-and-mouth disease vaccine," food Agric. Immunol., vol. 29, no. 1, pp. 470-483, 2018.

[94] W. Li, N. Maeda, and M. A. Beck, "Vitamin C Deficiency Increases the Lung Pathology of Influenza Virus - Infected,” Br. J. Nutr., vol. 136, no. 10, pp. 2611-2616, 2006.

[95] S. Alcocer, E. Bonilla, N. Valero, J. Salazar, and A. Melchor, "Melatonin , minocycline and ascorbic acid reduce oxidative stress and viral titers and increase survival rate in experimental Venezuelan equine encephalitis," brain Res., vol. 16, no. 22, pp. 368-376, 2015.

[96] A. Lallement, C. Zandotti, and P. Brouqui, "Persistent parvovirus B19 viremia with chronic arthralgia treated with ascorbic acid : a case report," J. Med. Case Rep., vol. 9, no. 1, pp. 9-12, 2015.

[97] H. Hemilä, "Does Vitamin C Alleviate the Symptoms of the Common Cold? - A Review of Current Evidence Does Vitamin C Alleviate the Symptoms of the Common," Scand. J. Infect. Dis., vol. 26, no. 1, pp. 1-6, 1994

[98] H. Hemilä, E. Chalker, and B. Douglas, "Vitamin C for preventing and treating the common cold ( Review )," Cochrane Database Syst. Rev., 2007.

[99] A. A. Fowler et al., "Intravenous vitamin C as adjunctive therapy for enterovirus/rhinovirus induced acute respiratory distress syndrome," World J. Crit. Care Med., vol. 6, no. 1, pp. 85-91, 2017.

[100] M. A. Beck, Q. Shi, M. Virginia C, and O. A. Levander, "Rapid genomic evolution of a non-virulent Coxsackievirus B3 in selenium-deficient mice results in selection of identical virulent isolates," Nat. Med., vol. 1, pp. 433-436, 1995.

[101] A. J. W. te Velthuis, S. H. E. van den Worml, A. C. Sims, R. S. Baric, E. J. Snijder, and M. J. van Hemert, "Zn2+ inhibits coronavirus and arterivirus RNA polymerase activity in vitro and zinc ionophores block the replication of these viruses in cell culture," PLOS Pathog., vol. 6, no. 11, 2010.

[102] S. A. Read, S. Obeid, C. Ahlenstiel, and G. Ahlenstiel, "The Role of Zinc in Antiviral Immunity," Adv. Nutr., vol. 10, no. 4, pp. 696-710, 2019.

[103] P. J. Fraker, P. DePasquale-Jardieu, C. M. Zwickl, and R. W. Luecke, "Regeneration of T-cell helper function in zinc-deficient adult mice,” Proc. Natl. Acad. Sci. U. S. A., vol. 75, no. 11, pp. 5660-5664, 1978.

[104] P. J. Fraker, M. E. Gershwin, R. A. Good, and A. Prasad, "Interrelationships between zinc and immune function.," Fed. Proc., vol. 45, no. 5, pp. 1474-1479, Apr. 1986.

[105] J. A. Acevedo-Murillo, M. L. Garcia Leon, V. Firo-Reyes, J. L. Santiago-Cordova, A. P. GonzalezRodriguez, and R. M. Wong-Chew, "Zinc Supplementation Promotes a Th1 Response and Improves Clinical Symptoms in Fewer Hours in Children With Pneumonia Younger Than 5 Years Old. A Randomized Controlled Clinical Trial.," Front. Pediatr., vol. 7, p. 431, 2019.

[106] J. D. Kruse-Jarres, "The significance of zinc for humoral and cellular immunity.," J. Trace Elem. Electrolytes Health Dis., vol. 3, no. 1, pp. 1-8, Mar. 1989.

[107] C. T. Walsh, H. H. Sandstead, A. S. Prasad, P. M. Newberne, and P. J. Fraker, "Zinc: health effects and research priorities for the 1990s.," Environ. Health Perspect., vol. 102 Suppl, pp. 5-46, Jun. 1994.

[108] L. Schlesinger, M. Arevalo, S. Arredondo, B. Lonnerdal, and A. Stekel, "Zinc supplementation impairs monocyte function.," Acta Paediatr., vol. 82, no. 9, pp. 734-738, Sep. 1993.

[109] C. Li, Y. Li, and C. Ding, "The role of copper homeostasis at the host-pathogen axis: From bacteria to fungi,” Int. J. Mol. Sci., vol. 20, no. 1, pp. 1-15, 2019.

[110] D. Miyamoto et al., "Thujaplicin-copper chelates inhibit replication of human influenza viruses.," Antiviral Res., vol. 39, no. 2, pp. 89-100, Aug. 1998.

[111] J. C. Rupp et al., "Host Cell Copper Transporters CTR1 and ATP7A are important for Influenza A virus replication.,"Virol. J., vol. 14, no. 1, p. 11, Jan. 2017.

[112] J. R. Stabel, J. W. Spears, and T. T. J. Brown, "Effect of copper deficiency on tissue, blood characteristics, and immune function of calves challenged with infectious bovine rhinotracheitis virus and Pasteurella hemolytica.," J. Anim. Sci., vol. 71, no. 5, pp. 1247-1255, May 1993.

[113] J. Prohaska and M. Failla, Copper and immunity. In Nutrition and Immunology. New York and London: Plenum Press, 1993.

[114] J. R. Turnlund et al., "Long-term high copper intake: effects on indexes of copper status, antioxidant status, and immune function in young men.," Am. J. Clin. Nutr., vol. 79, no. 6, pp. 1037-1044, Jun. 2004

[115] D. S. Kelley, P. A. Daudu, P. C. Taylor, B. E. Mackey, and J. R. Turnlund, "Effects of low-copper diets on human immune response.," Am. J. Clin. Nutr., vol. 62, no. 2, pp. 412-416, Aug. 1995

[116] M. P. Rayman, "Selenium and human health.," Lancet (London, England), vol. 379, no. 9822, pp. 12561268, Mar. 2012.

[117] J. Chaudiere, E. C. Wilhelmsen, and A. L. Tappel, "Mechanism of selenium-glutathione peroxidase and its inhibition by mercaptocarboxylic acids and other mercaptans.," J. Biol. Chem., vol. 259, no. 2, pp. 10431050, Jan. 1984.

[118] K. B. Beckman and B. N. Ames, "Oxidative decay of DNA.," J. Biol. Chem., vol. 272, no. 32, pp. 1963319636, Aug. 1997. 
[119] C. S. Broome et al., "An increase in selenium intake improves immune function and poliovirus handling in adults with marginal selenium status.," Am. J. Clin. Nutr., vol. 80, no. 1, pp. 154-162, Jul. 2004.

[120] K. Ivory et al., "Selenium supplementation has beneficial and detrimental effects on immunity to influenza vaccine in older adults.," Clin. Nutr., vol. 36, no. 2, pp. 407-415, Apr. 2017.

[121] W. C. Hawkes, A. Hwang, and Z. Alkan, "The effect of selenium supplementation on DTH skin responses in healthy North American men.," J. Trace Elem. Med. Biol., vol. 23, no. 4, pp. 272-280, 2009.

[122] S. Chandra and R. K. Chandra, "Nutrition, immune response, and outcome.," Prog. Food Nutr. Sci., vol. 10, no. 1-2, pp. 1-65, 1986.

[123] M. Tam, S. Gómez, M. González-Gross, and A. Marcos, "Possible roles of magnesium on the immune system,” Eur. J. Clin. Nutr., vol. 57, no. 10, pp. 1193-1197, 2003.

[124] B. Chaigne-Delalande et al., "Mg2+ regulates cytotoxic functions of NK and CD8 T cells in chronic EBV infection through NKG2D.," Science, vol. 341, no. 6142, pp. 186-191, Jul. 2013.

[125] R.-Y. Liang, W. Wu, J. Huang, S.-P. Jiang, and Y. Lin, "Magnesium affects the cytokine secretion of CD4(+) T lymphocytes in acute asthma.," J. Asthma, vol. 49, no. 10, pp. 1012-1015, Dec. 2012.

[126] K. J. Horning, S. W. Caito, K. G. Tipps, A. B. Bowman, and M. Aschner, "Manganese Is Essential for Neuronal Health," Annu. Rev. Nutr., vol. 35, no. 1, pp. 71-108, Jul. 2015.

[127] G. F. Kwakye, M. M. B. Paoliello, S. Mukhopadhyay, A. B. Bowman, and M. Aschner, "Manganeseinduced parkinsonism and Parkinson's disease: Shared and distinguishable features," Int. J. Environ. Res. Public Health, vol. 12, no. 7, pp. 7519-7540, 2015.

[128] C. Wang et al., "Manganese Increases the Sensitivity of the cGAS-STING Pathway for Double-Stranded DNA and Is Required for the Host Defense against DNA Viruses," Immunity, vol. 48, no. 4, pp. 675-687.e7, 2018.

[129] K. J. Waldron, J. C. Rutherford, D. Ford, and N. J. Robinson, “Metalloproteins and metal sensing,” Nature, vol. 460, no. 7257, pp. 823-830, 2009.

[130] H. Haase, “Innate Immune Cells Speak Manganese,” Immunity, vol. 48, no. 4, pp. 616-618, 2018.

[131] L. Zhang and Y. Liu, "Potential interventions for novel coronavirus in China: A systematic review," J. Med. Virol., vol. 92, no. 5, pp. 479-490, 2020.

[132] A. Soyano and M. Gomez, "[Role of iron in immunity and its relation with infections].," Arch. Latinoam. Nutr., vol. 49, no. 3 Suppl 2, pp. 40S-46S, Sep. 1999.

[133] M. U. Imam, S. Zhang, J. Ma, H. Wang, and F. Wang, "Antioxidants mediate both iron homeostasis and oxidative stress," Nutrients, vol. 9, no. 7, pp. 1-19, 2017.

[134] M. Wessling-Resnick, "Crossing the Iron Gate: Why and How Transferrin Receptors Mediate Viral Entry," Annu. Rev. Nutr., vol. 38, no. 1, pp. 431-458, 2018.

[135] P. George, "A comparison of the decomposition of hydrogen peroxide by catalase, ferrous and ferric ions, haemin and ferrous phthalocyanine.," Biochem. J., vol. 43, no. 2, pp. 287-295, 1948.

[136] J. A. A. S. Jayaweera, M. Reyes, and A. Joseph, "Childhood iron deficiency anemia leads to recurrent respiratory tract infections and gastroenteritis," Sci. Rep., vol. 9, no. 1, pp. 1-8, 2019. 